\title{
Physical Activity Participation During the COVID-19 Pandemic
}

\author{
Taemin Ha \& Brian Dauenhaver \\ University of Northern Colorado
}

\section{Introduction}

Physical activity is a significant factor in enhancing quality of life due to its various physical and mental benefits. According to the World Health Organization (WHO, 2010), the recommended amount of physical activity for adults (>17 years old) is a minimum of 150 minutes of moderate-intensity activity or 75 minutes of vigorous-intensity activity every week, while the recommended amount for children and adolescents (5-17 years old) is at least 60 minutes of moderate-to-vigorous physical activity daily. However, when coronavirus disease 2019 (COVID-19) was declared a pandemic on March 1 1 th, 2020 (WHO, 2020a), people around the world had to adapt to new lifestyles involving shelter-in-place and social distancing orders. This phenomenon has disrupted the ability to reach the recommended amount of physical activity for people of all ages (Carvalho \& Gois, 2020). The sedentary behaviors adopted during this unprecedented time could, for many people, give rise to an unhealthy lifestyle, which by extension may lead to an increased risk of coronavirus. The purpose of this paper is to review the issue and discuss ways to participate in health-enhancing physical activity during the COVID-19 pandemic.

Keywords: health, exercise, coronavirus

Article History

Received 11 September 2020

Accepted 28 September 2020

Published 31 October 2020

Available online 31 December 2020

https://doi.org/10.47544/johsk.2020.1.1.32
Corresponding Author

Taemin $\mathrm{Ha}$

taemin.ha@unco.edu

School of Sports and Exercise Science

College of Natural and Health Sciences

University of Northern Colorado, USA

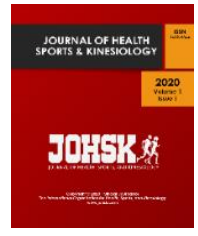

\section{Overview}

The latest report of Global Health Observatory (GHO) data has shown that $27.5 \%$ of adults (older than 18 years old) are physically inactive, and $81 \%$ of school-aged youth ( 6 to 17 years old) are not meeting global recommendations for physical activity (WHO, 2016). Furthermore, the number of obese adults throughout the world has nearly tripled since 1975 and is now over 650 million, while obesity rates of children have risen to more than 340 million (WHO, $2020 b$ ). These facts were reported before the pandemic began, and this has led to even fewer opportunities for physical activity (Sallis et al., 2020).

Participation in physical activity helps to reduce the risk of developing health conditions such as obesity, cancer, osteoporosis, type 2 diabetes, heart disease, and high blood pressure (U.S. Department of Health and Human Services, 2018), all of which can increase susceptibility to COVID-19 (Kalligeros et al., 2020; Shah et al., 2020;

\section{Journal of Health Sports \& Kinesiology | ISSN 2692-9864 | www.johsk.com}


| 2020 | Volume 1 | Issue 1 | The Journal of Health, Sports, and Kinesiology |

Yu et al., 2020). In addition, a number of studies have proven that low levels of physical activity are associated with an increased prevalence of anxiety and depression (Korczak et al., 2017; Stubbs et al., 2017). The lockdown has resulted in reduced opportunities for physical activity, as many indoor and outdoor sports, leisure activities, and recreational facilities, such as gyms, playgrounds, and public swimming pools, are unavailable in many countries (Shahidi et al., 2020). Thus, doing intentional physical activity at home or while practicing proper social distancing outdoors should be considered as a strategy for maintaining both a healthy body and mind.

\section{Considerations}

With the continuance of COVID-19, a variety of home-based physical activities have been proposed and recommended by many different scholars, experts, and organizations. For example, the American College of Sports Medicine (ACSM, 2020) recently released information on how to stay physically active during the COVID-19 pandemic, including diverse home-based aerobic activities and strength training. In addition, the Society of Health and Physical Educators (SHAPE) America (2020) has provided K-12 health and physical education teachers with at-home fitness ideas that they can incorporate into their teaching curriculum for both synchronous and asynchronous remote instruction. Exercising at home with these and other safe, simple, and easily implementable workout routines is a suitable way to maintain physical fitness and mental health while avoiding COVID-19 (MarcosPardo et al., 2020).

A specific form of exercise that is considered a great home-based physical activity to help maintain cardiovascular, metabolic, and musculoskeletal fitness and decrease the severity of depression is dance (Hammami et al., 2020). There are many types of dances, such as contemporary, jazz, salsa, and hip-hop, that embrace the use of diverse body movements and routines that require both flexibility and strength. Dance, often considered a universal language, knows no cultural barriers; every culture includes some type of dance that is accompanied by music, which helps regulate emotions, provides comfort, and improves cognition (Alpert, 2011). As a sustainable form of physical activity and a fundamental of the arts, dance allows all ages of people to stay fit and benefits both musculoskeletal and psychological health.

Resistance training is another exercise that is well-suited as a home-based physical activity that can help increase muscle strength and functional capacity, especially in older adults who may be more concerned about contracting COVID-19. Marcos-Padro et al. (2020) introduced home elastic-resistance training recommendations for older adults following the Position Statement of Resistance Training for Older Adults (Fragala et al., 2019) from the National Strength and Conditioning Association (NSCA) and the ACSM's Guidelines for Exercise Testing and Prescription (Pescatello et al., 2014). The recommendations consist of nine different movements: (a) elbow curl, (b) squat, (c) elbow extension, (d) knee extension, (e) chest press, (f) leg press, (g) shoulder overhead press, (h) knee curl, and (i) shoulder seated row. By following these recommendations, older adults can also do physical self-care that is safe, simple, effective, and low-cost.

The emergence of COVID-19 has created extraordinary challenges. Rather than preparing for a life postCOVID-19, people around the world may need to figure out how to live with its existence. In response to the concern, an international group of researchers and investigators who have interdisciplinary expertise in behavioral science, spatial epidemiology, urban health, physiotherapy, and health promotion, have proposed and been conducting studies to evaluate interventions of various types during the context of the current pandemic (Sallis et al., 2020). The research team believes those results could be directly applicable to improving responses to the current and future crises. Recent research by Carvalho and Gois (2020) supports that it is still possible to meet the WHO recommendations for physical activity while spending most of one's time at home during the pandemic situation. Home-based physical activity enables people of all ages to remain fit and healthy while still following stay-at-home policies. Although the pandemic situation will, at some point, end, until then, hopefully the world will recognize the efficacy of home-based physical activity.

\section{References}

Alpert, P. T. (2011). The health benefits of dance. Home Health Care Management \& Practice, 23(2), $155-157$. American College of Sports Medicine. (2020, August 4). Staying Active During the Coronavirus Pandemic. https://www.exerciseismedicine.org/assets/page_documents/EIM_Rx\%20for\%20Health_\%20Staying\%20Activ e\%20During\%20Coronavirus\%20Pandemic.pdf

Carvalho, V. O., \& Gois, C. O. (2020). COVID-19 pandemic and home-based physical activity. The Journal of Allergy and Clinical Immunology: In Practice. https://doi.org/10.1016/j.jaip.2020.05.018

Journal of Health Sports \& Kinesiology | ISSN 2692-9864 | www.johsk.com

Page | 33 
| 2020 | Volume 1 | Issue 1 | The Journal of Health, Sports, and Kinesiology |

Fragala, M. S., Cadore, E. L., Dorgo, S., Izquierdo, M., Kraemer, W. J., Peterson, M. D., \& Ryan, E. D. (2019). Resistance training for older adults: position statement from the national strength and conditioning association. The Journal of Strength \& Conditioning Research, 33(8), 2019-2052. https://doi.org/10.1519/JSC.0000000000003230

Hammami, A., Harrabi, B., Mohr, M., \& Krustrup, P. (2020). Physical activity and coronavirus disease 2019 (COVID19): Specific recommendations for home-based physical training. Managing Sport and Leisure, 1-6. https://doi.org/10.1080/23750472.2020.1757494

Kalligeros, M., Shehadeh, F., Mylona, E. K., Benitez, G., Beckwith, C. G., Chan, P. A., \& Mylonakis, E. (2020). Association of obesity with disease severity among patients with coronavirus disease 2019. Obesity, 28(7) 1200-1204. https://doi.org/10.1002/oby.22859

Korczak, D. J., Madigan, S., \& Colasanto, M. (2017). Children's physical activity and depression: A metaanalysis. Pediatrics, 139(4).

Marcos-Pardo, P. J., Espeso-García, A., López-Vivancos, A., Abelleira Lamela, T., \& Keogh, J. W. L. (2020). COVID-19 and social isolation: A case for why home-based resistance training is needed to maintain musculoskeletal and psychosocial health for older adults. Journal of Aging and Physical Activity, 1, 1-7. https://doi.org/10.1123/japa.2020-0131

Sallis, J. F., Adlakha, D., Oyeyemi, A., \& Salvo, D. (2020). An international physical activity and public health research agenda to inform COVID-19 policies and practices. Journal of Sport and Health Science. https://doi.org/10.1016/j.jshs.2020.05.005

Shah, P. B., Welt, F. G., Mahmud, E., Phillips, A., Kleiman, N. S., Young, M. N., ... \& Wyman, J. (2020). Triage considerations for patients referred for structural heart disease intervention during the COVID-19 pandemic: An ACC/SCAI position statement. JACC: Cardiovascular Interventions, 13(12), 1484-1488. https://doi.org/10.1002/ccd.28910

Shahidi, S. H., Stewart Williams, J., \& Hassani, F. (2020). Physical activity during COVID-19 quarantine. Acta Paediatrica. https://doi.org/10.1111/apa.15420

SHAPE America - Society of Health and Physical Educators (2020, August 31). COVID-19 resources. https://www.shapeamerica.org/covid19-resources.aspx

Stubbs, B., Koyanagi, A., Hallgren, M., Firth, J., Richards, J., Schuch, F., ... \& Vancampfort, D. (2017). Physical activity and anxiety: A perspective from the World Health Survey. Journal of affective disorders, 208, 545-552. https://doi.org/10.1016/j.jad.2016.10.028Get

Pescatello, L. S., Riebe, D., \& Thompson, P. D. (Eds.). (2014). ACSM's guidelines for exercise testing and prescription. Lippincott Williams \& Wilkins.

US Department of Health and Human Services. (2018). Physical activity guidelines for Americans, 2nd edition. https://health.gov/sites/default/files/2019-09/Physical_Activity_Guidelines_2nd_edition.pdf

World Health Organization. (2010). Global recommendations on physical activity for health. Geneva, Switzerland: World Health Organization.

World Health Organization. (2016). Global Health Observatory (GHO) data: Prevalence of insufficient physical activity. https://www.who.int/gho/ncd/risk_factors/physical_activity_text/en/

World Health Organization (2020a, March 11). WHO director-general's opening remarks at the media briefing on COVID-19, 11 March 2020.

https://www.who.int/dg/speeches/detail/who-director-general-s-opening-remarks-at-the-mediabriefing-on-covid-19,11-March-2020

World Health Organization (2020b, April 1). Obesity and overweight. https://www.who.int/news-room/fact-sheets/detail/obesity-and-overweight

Yu, E. W., Tsourdi, E., Clarke, B. L., Baver, D. C., \& Drake, M. T. (2020). Osteoporosis management in the era of COVID19. Journal of Bone and Mineral Research, 35(6), 1009-1013. https://doi.org/10.1002/jbmr.4049 